\title{
THE PULMONARY PHYSIOLOGY OF NORMAL INDIVIDUALS LIVING AT AN ALTITUDE OF ONE MILE ${ }^{1}$
}

\author{
By LEIGHTON L. ANDERSON, MARY L. WILLCOX, JOAN SILLIMAN, AND \\ S. GILBERT BLOUNT, JR.
}

\begin{abstract}
(From the Cardiovascular Pulmonary Laboratory, Department of Medicine, University of Colorado School of Medicine, Denver, Colo.)
\end{abstract}

(Submitted for publication January 27, 1953; accepted February 25, 1953)

Pulmonary physiology has been studied extensively by many investigators, and a voluminous literature has resulted from these studies. However, almost all observations have been made at or near sea level, with only a few studies on thoroughly acclimatized persons at this median altitude. Since there is a significant section of this country where people live at an altitude of 5,000 to 8,000 feet, it was thought desirable to determine the effect of this altitude upon pulmonary function. Therefore, the pulmonary function of a group of healthy, thoroughly acclimatized persons has been evaluated and the results obtained are compared with similar studies performed at sea level.

\section{METHODS AND PROCEDURES}

1) Maximum breathing capacity (maximum voluntary minute ventilation). The maximum breathing capacity was determined using a mask, a two-way high velocity valve, and large corrugated rubber tubing. The expired air was collected in a Douglas bag. The subject, encouraged to perform maximally, breathed as rapidly and deeply as possible for 30 seconds. The collected expired air was transferred to a large spirometer for measurement of volume which was then corrected to $37^{\circ} \mathrm{C}$. saturated and ambient pressure (BTPS). After a minimal twenty minute rest period the test was repeated and the largest value obtained was recorded.

2) Resting minute ventilation and gas exchange. For these measurements a mouthpiece, nose clip, and a low resistance two-way valve with a deadspace of $64 \mathrm{cc}$. were used. The two-way valve was connected by corrugated rubber tubing to a Douglas bag in which the expired air was collected. The subject was allowed to rest supine for at least twenty minutes prior to the test to assure a relatively stable resting state. Expired air was collected for six minutes, beginning at the end of a quiet expiration. The expired air was immediately transferred to a spirometer for measurement of volume. During the transfer a sample was removed for analysis of oxygen

1 This study was supported by a grant (H-241) from the United States Public Health Service with additional support provided by a grant (CTAE-100) from the National Foundation for Infantile Paralysis, Inc. and carbon dioxide content with the Haldane apparatus. The minute ventilation in liters at $37^{\circ} \mathrm{C}$., saturated and at ambient pressure (BTPS) was determined. Oxygen consumption and carbon dioxide output in cc. per minute were calculated at standard conditions (STPD). The respiratory quotient and the rate of oxygen removal were also determined. Finally, minute ventilation, oxygen consumption, and carbon dioxide output were calculated for each square meter of body surface.

3) Exercise minute ventilation and gas exchange. Essentially the same procedure as that for resting ventilation was repeated during exercise on the treadmill; the only real difference was in the use of an oro-nasal mask and head harness instead of a mouthpiece and nose clip. In the first test, the subjects exercised on a treadmill at 2.5 miles per hour on the level for 10 minutes. The expired air was collected for three, four, and three minute divisions of this exercise period and similarly during a 10 minute recovery period with the subject seated. In the second exercise procedure the expired air was collected during the fifth and sixth minutes of exercise at 3.5 miles per hour at the maximum incline of the treadmill or at the maximum incline tolerated. In all but two instances the individuals were able to walk at the maximum incline of the treadmill which is 22 per cent.

4) Peripheral arterial and alveolar respiratory gas values at rest and during exercise. With the subject supine, an in-dwelling Cournand needle was placed in the brachial artery. After a rest period of five to ten minutes an initial sample of arterial blood was withdrawn in an oiled and heparinized syringe. A small drop of mercury was immediately placed into the syringe anaerobically, and the syringe was sealed with a needle and rubber stopper. After adequate agitation to prevent clotting the syringe was placed in an ice bath. The contents of oxygen and carbon dioxide and the capacity of oxygen of the blood sample were determined within two hours by the manometric technique of Van Slyke and Neill (1). Following withdrawal of the above sample, another sample was obtained in an unoiled heparinized syringe simultaneously with the collection of the expired air. The blood and expired air samples were collected during a period of one and a half minutes. The oxygen and carbon dioxide tensions of the arterial blood sample were immediately determined by the method of Riley, Proemmel, and Franke (2). The collected expired air was immediately measured and sampled and the percentages of oxygen and carbon dioxide determined by 
the Scholander micro gas analysis method (3). Using the data obtained, the alveolar oxygen tension and the alveolar-arterial oxygen tension gradient were determined by the methods described by Riley, Lilienthal, Proemmel, and Franke (4) and by Lilienthal and associates (5).

Finally, samples of blood and expired air were similarly collected during a moderate amount of exercise pedalling a bicycle arrangement while still supine. The same analyses and calculations were completed for this exercise state.

\section{RESULTS}

Maximum breathing capacity (maximum voluntary minute ventilation). The values obtained for the maximum breathing capacity for both sexes and successive age groups are shown in Table I along with those reported at sea level (6). The evident decrease in the maximum breathing capacity associated with the ageing process is apparent. Recently, it has been emphasized (7) that there have been but few measurements of pulmonary function in older persons, although it is generally accepted that there is a decrease in ventilatory function with increasing age. The maximum breathing capacity is somewhat higher for all groups in this series when compared with that recorded at sea level (6); however, the mean values reported more closely approximate the usually accepted values. The method employed in this study has minimal resistance; furthermore, the persons tested were healthy, active students and employees and not hospital patients without evident cardio-pulmonary disease. These facts may account for the higher values in the subjects in this study. It is not evident that this median altitude has altered significantly the maximum breathing capacity.

Resting minute ventilation and gas exchange.
The data obtained by this procedure are presented with those obtained at sea level (6) in Table II. It would appear that the differences are statistically significant. It is evident that resting minute ventilation is increased by this median altitude. The R.Q. was less than 1.00 in all but three individuals and the mean for the entire group was 0.84 . Therefore, hyperventilation played no part in the increased minute ventilation.

Exercise minute ventilation and gas exchange. Data regarding exercise minute ventilation and gas exchange are shown in Tables III, IV, and V. The values for minute ventilation and oxygen consumption during the ten minutes of mild exercise (Table III) indicate that the subjects readily reached a stable exercise state. Since the measurements of ventilation during recovery were made with the subjects seated instead of supine, it would appear that recovery was complete at the end of three minutes. Statistical analyses of these ventilatory and oxygen consumption values are presented in Table IV. Maximum exercise tolerance was not obtained in all instances since a 22 per cent incline was the greatest possible under existing circumstances. The available data are shown in Table V. Some of the individuals could have performed more work, however; a greater speed would have resulted in a near running state which would have been more difficult for some than for others. Therefore, the speed was not increased to obtain maximum exercise tolerance in those individuals. The pulse rate for 30 seconds immediately following maximum exercise is also recorded in Table V.

Peripheral arterial and alveolar respiratory gas values at rest and during exercise. The data for this procedure are given in Table VI. The mean

TABLE I

Standing maximum breathing capacity in liters per minute at $37^{\circ}$ saturated

\begin{tabular}{|c|c|c|c|c|c|c|c|c|c|c|c|c|c|c|c|}
\hline \multirow[b]{2}{*}{ Males } & \multicolumn{5}{|c|}{ Age 16-34 years } & \multicolumn{5}{|c|}{ Age 35-49 years } & \multicolumn{5}{|c|}{ Age $50-70$ years } \\
\hline & No. & Mean & S.D. & S.E. & Range & No. & Mean & S.D. & S.E. & Range & No. & Mean & S.D. & S.E. & Range \\
\hline \multirow{2}{*}{$\begin{array}{l}\text { Anderson et al. } \\
\text { (Alt. } 5,300 \mathrm{ft} \text { ) } \\
\text { Baldwin et al. } \\
\text { (Sea level) }\end{array}$} & 38 & 172 & 33 & 5.43 & 99-237 & 15 & 150 & 32.6 & 8.72 & 69-197 & 16 & 93.8 & 31.8 & 8.22 & $56-181$ \\
\hline & 17 & 126 & 28.6 & & $82-169$ & 15 & 109.4 & 15.9 & & $86-144.5$ & 18 & 90.6 & 16.8 & & $58-139$ \\
\hline \multicolumn{16}{|l|}{ Females } \\
\hline Anderson et al. & 52 & 102.7 & 17.0 & 2.38 & $66-139$ & 15 & 96.3 & $21: 0$ & 5.62 & $50-134$ & 15 & 91.4 & 15.4 & 4.12 & $66-124$ \\
\hline $\begin{array}{l}\text { (Alt. } 5,300 \mathrm{tt} .) \\
\text { Baldwin et al. } \\
\text { (Sea level) }\end{array}$ & 15 & 93.7 & 12.6 & & $63.6-117.5$ & 10 & 89.3 & 17.9 & & $47-114$ & 13 & 73.5 & 16.8 & & 49-101.5 \\
\hline
\end{tabular}




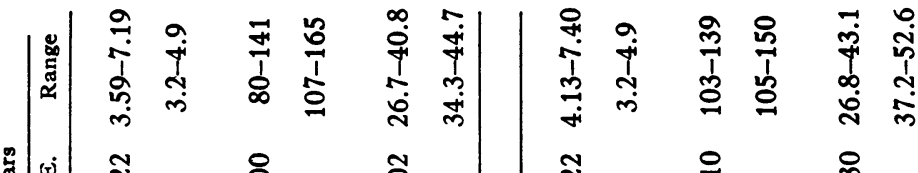

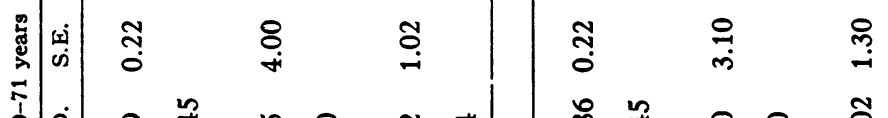

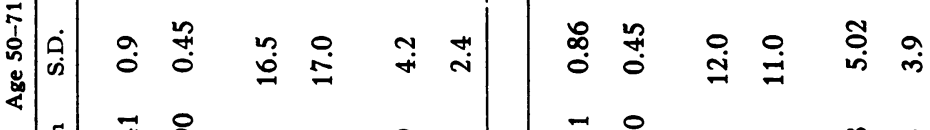

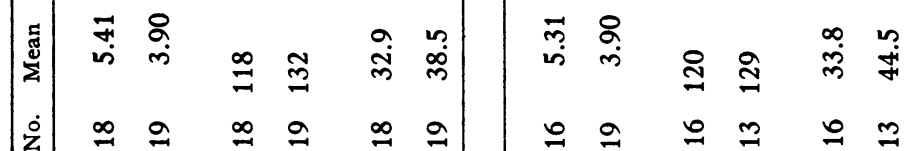

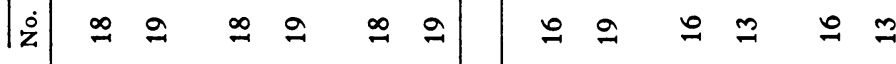

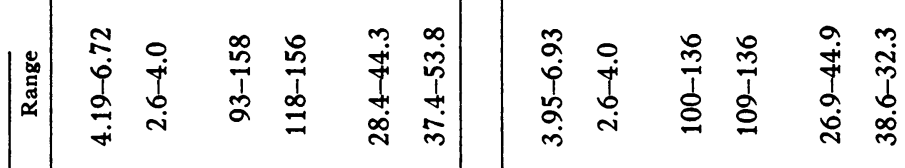

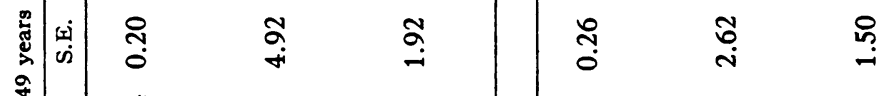

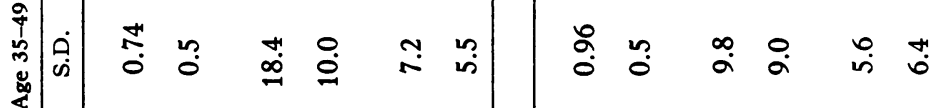

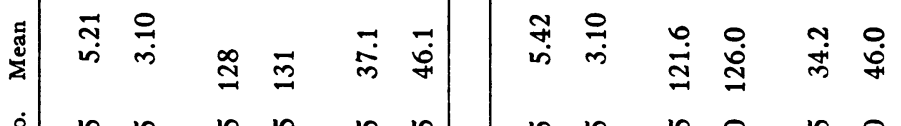

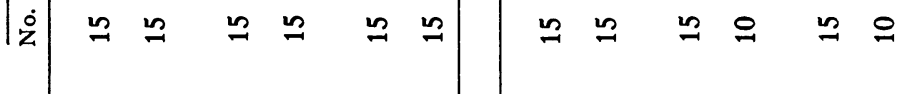

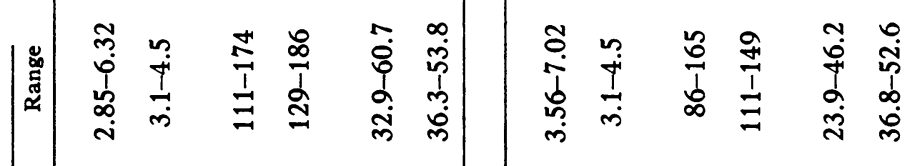

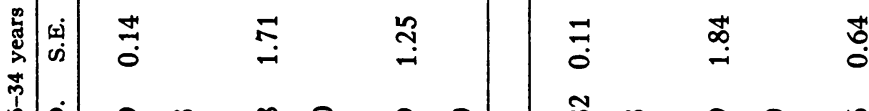

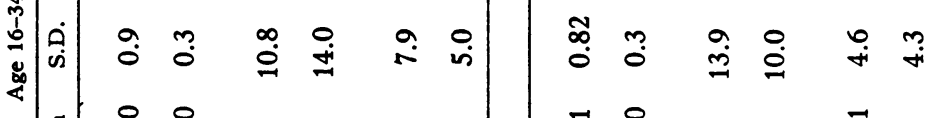

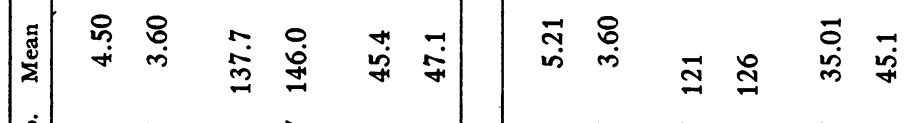

$$
\begin{aligned}
& \text { i⿱ } \vec{F}=\vec{F}=\vec{F}=\text { in }=\text { in }=\text { in }
\end{aligned}
$$

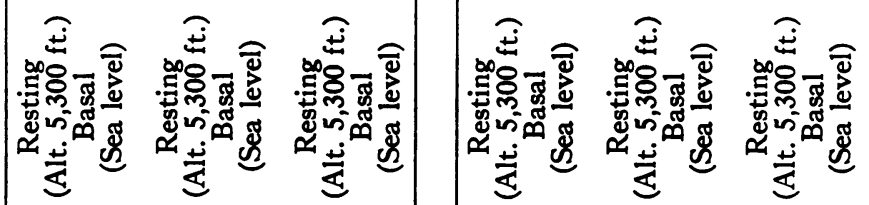

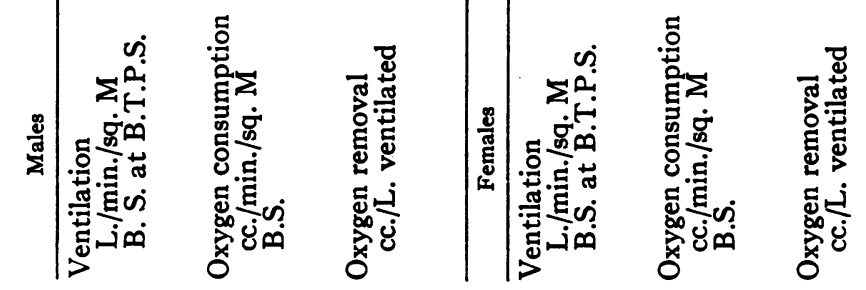


TABLE III

Minute ventilation'and gas exchange response to walking on the level at $2.5 \mathrm{mph}$. for 10 minutes

\begin{tabular}{|c|c|c|c|c|c|c|c|}
\hline \multirow[b]{2}{*}{ Males (15) Ave. age 34 yrs. } & \multirow{2}{*}{$\begin{array}{l}\text { Rest* } \\
6 \mathrm{~min} .\end{array}$} & \multicolumn{3}{|c|}{ Exercise (10 min.) } & \multicolumn{3}{|c|}{ Recovery (10 min.) } \\
\hline & & $3 \mathrm{~min}$. & $4 \mathrm{~min}$. & $3 \mathrm{~min}$. & $3 \mathrm{~min}$. & $4 \mathrm{~min}$. & $3 \mathrm{~min}$. \\
\hline \multirow{3}{*}{$\begin{array}{l}\text { Ventilation in L./min./sq. M } \\
\text { B.S. (B.T.P.S.) } \\
\mathrm{O}_{2} \text { Cons. in cc./min./sq. M } \\
\text { B.S. (S.T.P.D.) } \\
\text { Rate of } \mathrm{O}_{2} \text { removal in cc./L. } \\
\text { vent. }\end{array}$} & 4.63 & 13.0 & 13.39 & 13.4 & 7.72 & 6.62 & 6.42 \\
\hline & 136 & 465 & 472 & 455 & 215 & 169 & 153 \\
\hline & 44.7 & 53.4 & 52.5 & 50.4 & 41.5 & 37.3 & 37.0 \\
\hline \multicolumn{8}{|l|}{ Females (16) Axe. age 30 yrs. } \\
\hline \multirow{3}{*}{$\begin{array}{l}\text { Ventilation in L./min./sq. M } \\
\text { B.S. (B.T.P.S.) } \\
\mathrm{O}_{2} \text { Cons. in cc./min./sq. M } \\
\text { B.S. (S.T.P.D.) } \\
\text { Rate of } \mathrm{O}_{2} \text { removal in cc./L. } \\
\text { vent. }\end{array}$} & 5.12 & 14.6 & 15.5 & 15.2 & 9.01 & 7.1 & 6.68 \\
\hline & 125 & 426 & 434 & 407 & 205 & 137 & 131 \\
\hline & 37.3 & 44.4 & 42.6 & 40.4 & 34.3 & 28.7 & 29.7 \\
\hline
\end{tabular}

* Resting values obtained in supine position.

B.T.P.S.-Body temperature, prevailing pressure saturated.

R.Q. during exercise was 0.96 as compared with 0.79 at rest. The resultant hyperventilation increased the mean alveolar oxygen tension, but was not particularly effective in increasing the mean arterial oxygen tension. There was a resultant increase in the alveolar-arterial oxygen tension gradient with exercise. The arterial carbon dioxide tension remained the same during exercise. The exercise was of a moderate nature because the resting mean minute ventilation and oxygen consumption per square meter of body surface were quadrupled by exercise.

\section{DISCUSSION}

The establishment of normal values for tests employed in the evaluation of the pulmonary function in healthy acclimatized persons living at an altitude of one mile was one of the aims of this study. It might be well to emphasize that the values obtained by these procedures at any given elevation depend, in part, upon the methods used. The fact that the subjects of this study were healthy and gainfully employed persons and not hospital patients without evidences of cardio-pulmonary disease is also of importance in the evaluation of these results.

However, the primary consideration of this study was the evaluation of the effect of an altitude of one mile upon pulmonary function of normal individuals. This can be ascertained only by comparing results obtained at this altitude with those obtained at sea level.

Maximum breathing capacity (maximum voluntary minute ventilation). There is no evidence

TABLE IV

Mean minute ventilation and oxygen consumption and rate of oxygen removal during exercise and recovery of 31 acclimated persons

(2.5 $\mathrm{mph}$. on the level for 10 minutes and a recovery period of 10 minutes)

\begin{tabular}{|c|c|c|c|c|c|c|c|}
\hline & & \multicolumn{3}{|c|}{ Males (15) } & \multicolumn{3}{|c|}{ Females (16) } \\
\hline & & Mean & S.D. & S.E. & Mean & S.D. & S.E. \\
\hline Age in years & & 34 & \pm 6.99 & \pm 1.87 & 30 & \pm 10.78 & \pm 2.79 \\
\hline $\begin{array}{l}\text { Ventilation in L./min./sq. M } \\
\text { B.S. (B.T.P.S.) }\end{array}$ & $\begin{array}{l}\text { Rest } \\
\text { Exercise } \\
\text { Recovery }\end{array}$ & $\begin{array}{r}4.61 \\
13.26 \\
6.85 \\
\end{array}$ & $\begin{array}{l} \pm 0.69 \\
\pm 1.52 \\
\pm 1.64 \\
\end{array}$ & $\begin{array}{l} \pm 0.18 \\
\pm 0.23 \\
\pm 0.25\end{array}$ & $\begin{array}{r}5.13 \\
15.10 \\
7.61 \\
\end{array}$ & $\begin{array}{l} \pm 0.96 \\
\pm 3.73 \\
\pm 1.65 \\
\end{array}$ & $\begin{array}{l} \pm 0.25 \\
\pm 0.54 \\
\pm 0.24 \\
\end{array}$ \\
\hline $\begin{array}{l}\mathrm{O}_{2} \text { Cons. in cc./min./sq. } \mathrm{M} \\
\text { B.S. (S.T.P.D.) }\end{array}$ & $\begin{array}{l}\text { Rest } \\
\text { Exercise } \\
\text { Recovery }\end{array}$ & $\begin{array}{l}138 \\
464 \\
179 \\
\end{array}$ & $\begin{array}{l} \pm 14.84 \\
\pm 38.02 \\
\pm 40.40\end{array}$ & $\begin{array}{l} \pm 3.97 \\
\pm 5.67 \\
\pm 6.09\end{array}$ & $\begin{array}{l}125 \\
423 \\
158 \\
\end{array}$ & $\begin{array}{l} \pm 14.69 \\
\pm 85.25 \\
\pm 41.31 \\
\end{array}$ & $\begin{array}{l} \pm 3.80 \\
\pm 12.30 \\
\pm \quad 5.96 \\
\end{array}$ \\
\hline $\begin{array}{l}\text { Rate of } \mathrm{O}_{2} \text { removal in } \\
\text { vol. } \%\end{array}$ & $\begin{array}{l}\text { Rest } \\
\text { Exercise } \\
\text { Recovery }\end{array}$ & $\begin{array}{l}4.55 \\
5.28 \\
3.91\end{array}$ & $\begin{array}{l} \pm 0.59 \\
\pm 0.63 \\
\pm 0.66\end{array}$ & $\begin{array}{l} \pm 0.16 \\
\pm 0.09 \\
\pm 0.10\end{array}$ & $\begin{array}{l}3.73 \\
4.25 \\
3.09\end{array}$ & $\begin{array}{l} \pm 0.65 \\
\pm 0.48 \\
\pm 0.47\end{array}$ & $\begin{array}{l} \pm 0.17 \\
\pm 0.07 \\
\pm 0.68\end{array}$ \\
\hline
\end{tabular}


TABLE $\mathbf{v}$

Ventilation and gas exchange at or near maximum exercise tolerance on the treadmill (20 healthy male subjects)

\begin{tabular}{lcccc}
\hline \hline & Mean & Range & S.D. & S.E. \\
\hline Age in years & 26.8 & $21-42$ & \pm 5.51 & \pm 1.26 \\
Ventilation in L./min./sq. M B.S. & 36.9 & $23.6-55.0$ & \pm 7.14 & \pm 1.64 \\
O $_{2}$ Cons. in L./min./sq. M B.S. & 1.172 & $0.762-1.532$ & \pm 0.1808 & \pm 0.0415 \\
Pulse rate at end of exercise & 144 & $100-178$ & \pm 20.5 & \pm 4.84 \\
\hline
\end{tabular}

that this altitude alters the maximum breathing capacity (Table I). Furthermore, since the volume of the maximum breathing capacity is a function of the capacity of the lungs and the effectiveness of the thoracic neuro-muscular system, and not dependent upon the metabolic requirements of the individual, there is no reason to expect alteration of this test at a median altitude. Rahn and Hammond (8), in an evaluation of the vital capacity, found that there was no significant change at elevations up to 10,000 feet. They did not comment upon the time necessary to perform the vital capacity.

Resting minute ventilation and gas exchange. Minute ventilation, however, would be affected by a reduced barometric pressure since this measurement is directly related to the supply and metabolic demands for oxygen. Average minute ventilation was 1.8 liters greater in this series than that observed at sea level (6) (Table II). Some of this increase in minute ventilation may be due to a difference in the metabolic states of the subjects in the two studies; however, it would not seem to be a difference as the values for oxygen consumption per minute are comparable in the two series.
A normal resting value of 3.4 liters per minute per square meter of body surface at sea level (9), and a mean resting value at sea level of 3.5 liters per minute per square meter (10) are reported. An acceptable mean value for resting minute ventilation per square meter of body surface at sea level appears to be 3.5 liters. The mean value for the entire group studied at this altitude was 5.08 liters, an increase of 1.5 liters, an increase of approximately 43 per cent. Schneider (11) quotes Fitzgerald who found an increase in the minute ventilation of approximately 15 per cent for each 5,000 feet increase in altitude. Gray (12) presents a graph which suggests a 15 per cent increase in the resting minute ventilation for an altitude of 5,000 feet.

Some of the increase in minute ventilation reported in this study may be due to the fact that all subjects were active students and employees who were not trained for the procedure. Furthermore, they came directly from their usual activity and were examined after only 20 minutes of rest. The inclusion of the older age groups may also be a factor in explaining the larger minute ventilation in this series. Most of the studies reported at sea level have not included older persons. Thus, for

TABLE VI

Arterial and alveolar respiratory gas values in 20 acclimatized healthy persons at an altitude of one mile

\begin{tabular}{|c|c|c|c|c|c|}
\hline & & Mean & Range & S.D. & S.E. \\
\hline $\begin{array}{l}\text { Arterial oxygen } \\
\text { saturation }\end{array}$ & $\begin{array}{l}\text { Rest } \\
\text { Exercise }\end{array}$ & $\begin{array}{l}94.1 \% \\
96.7 \%\end{array}$ & $\begin{array}{l}89.2-97.3 \\
92.5-100.0\end{array}$ & $\begin{array}{l}2.0 \\
2.26\end{array}$ & $\begin{array}{l}0.46 \\
0.52\end{array}$ \\
\hline $\begin{array}{l}\text { Alveolar oxygen } \\
\text { tension }\end{array}$ & $\begin{array}{l}\text { Rest } \\
\text { Exercise }\end{array}$ & $\begin{array}{l}79.6 \mathrm{~mm} . \mathrm{Hg} \\
86.0 \mathrm{~mm} . \mathrm{Hg}\end{array}$ & $\begin{array}{l}67.9-95.3 \\
77.5-98.8\end{array}$ & $\begin{array}{l}8.57 \\
4.91\end{array}$ & $\begin{array}{l}1.97 \\
1.13\end{array}$ \\
\hline $\begin{array}{l}\text { Arterial oxygen } \\
\text { tension }\end{array}$ & $\begin{array}{l}\text { Rest } \\
\text { Exercise }\end{array}$ & $\begin{array}{l}74.8 \mathrm{~mm} . \mathrm{Hg} \\
75.3 \mathrm{~mm} . \mathrm{Hg}\end{array}$ & $\begin{array}{l}68.7-85.7 \\
67.2-87.4\end{array}$ & $\begin{array}{l}5.54 \\
5.36\end{array}$ & $\begin{array}{l}1.27 \\
1.23\end{array}$ \\
\hline $\begin{array}{l}\text { Alveolar-arterial } \\
\text { oxygen tension gradient }\end{array}$ & $\begin{array}{l}\text { Rest } \\
\text { Exercise }\end{array}$ & $\begin{array}{r}4.8 \mathrm{~mm} . \mathrm{Hg} \\
10.7 \mathrm{~mm} . \mathrm{Hg}\end{array}$ & $\begin{array}{rr}-3.9- & 12.7 \\
4.6- & 21.5\end{array}$ & $\begin{array}{l}4.62 \\
5.0\end{array}$ & $\begin{array}{l}1.06 \\
1.15\end{array}$ \\
\hline $\begin{array}{l}\text { Arterial carbon } \\
\text { dioxide content }\end{array}$ & $\begin{array}{l}\text { Rest } \\
\text { Exercise }\end{array}$ & $\begin{array}{l}42.1 \text { vol. } \% \\
40.2 \text { vol. } \%\end{array}$ & $\begin{array}{l}36.6-47.5 \\
34.3-45.7\end{array}$ & $\begin{array}{l}2.94 \\
2.78\end{array}$ & $\begin{array}{l}0.67 \\
0.64\end{array}$ \\
\hline $\begin{array}{l}\text { Arterial carbon } \\
\text { dioxide tension }\end{array}$ & $\begin{array}{l}\text { Rest } \\
\text { Exercise }\end{array}$ & $\begin{array}{l}32.8 \mathrm{~mm} . \mathrm{Hg} \\
33.3 \mathrm{~mm} . \mathrm{Hg}\end{array}$ & $\begin{array}{l}23.0-39.5 \\
24.4-39.6\end{array}$ & $\begin{array}{l}5.43 \\
3.62\end{array}$ & $\begin{array}{l}1.24 \\
0.83\end{array}$ \\
\hline
\end{tabular}


these reasons the increase in minute ventilation in this series was probably not entirely produced by this median altitude. Furthermore, there are no known studies of minute ventilation at sea level which were performed and calculated in exactly the same manner as those presented in this study. However, it is clearly evident that minute ventilation is significantly increased at this median altitude.

Exercise minute ventilation and gas exchange. The mean minute ventilation was 14.18 liters per square meter (BTPS) for both sexes walking on the level at 2.5 miles per hour (Table IV). A value of 7.69 liters per minute per square meter near sea level (STPD) is reported (13). This increase in minute ventilation is due in part to the reduced barometric pressure. However, it is not possible to determine accurately the percentage increase of ventilation produced by this altitude since the results given by Bruce, Pearson, Lovejoy, $Y u$, and Brothers (13) are corrected to standard conditions. Furthermore, oxygen consumption was approximately 15 per cent greater in our series. Some of the increase in minute ventilation is therefore due to greater utilization of oxygen. The mean R.Q. for males was 0.81 and for females, 0.82 and all were less than 1.00. Hyperventilation was not, therefore, a cause of the larger ventilation volume. On correcting the value for the minute ventilation reported by Bruce, Pearson, Lovejoy, $\mathrm{Yu}$, and Brothers (13) to $37^{\circ} \mathrm{C}$. saturated and $760 \mathrm{~mm}$. $\mathrm{Hg}$, one obtains a value of 9.20 liters. There is an increase of 54 per cent in the exercise minute ventilation at this altitude. Thus, taking into consideration the 15 per cent increase in oxygen consumption there results a 40 per cent increase in the exercise ventilation, most of which is attributable to the lowered barometric pressure.

Maximum exercise tolerance. There are no known ventilatory values for a similar maximum exercise tolerance test available in the literature from sea level. However, the mean value of oxygen consumption was 1.17 liters per minute per square meter of body surface. Wright (14), in a similar study, obtained a mean value of oxygen consumption of 1.42 liters per minute per square meter of body surface. Our value for mean oxygen consumption is somewhat smaller than that re- ported by Wright. However, as previously described, maximum exercise tolerance was not obtained due to limitations of the treadmill.

It is noted that only five persons utilized more than 50 per cent of their ventilatory reserve during exercise and the mean for the group was 45 per cent. These figures indicate that ventilatory capacity is not the limiting factor for maximum exercise tolerance.

Arterial and alveolar gas values. The mean peripheral arterial oxygen saturation at rest of 94.1 per cent compares quite favorably with values reported in the literature for a similar altitude. Dill and Penrod (15) report 93 per cent saturation for 6,000 feet. The Handbook of Respiratory Data in Aviation reports 92-93 per cent saturation for 5,000 feet. Similarly, the mean alveolar oxygen tension of $79.6 \mathrm{~mm}$. at rest is comparable to the values reported in the literature.

The mean peripheral arterial oxygen tension of $74.8 \mathrm{~mm}$. at rest is comparable to the $70 \mathrm{~mm}$. reported by Dill and Penrod (15). The mean alveolar-arterial oxygen tension gradient at rest of 4.8 $\mathrm{mm}$. is similar to the gradient reported at sea level by other investigators $(5,9,16)$. Therefore, an arterial oxygen tension of $75 \mathrm{~mm}$. could be predicted in normal individuals at this altitude. The mean peripheral arterial carbon dioxide tension of $33 \mathrm{~mm}$. $\mathrm{Hg}$ is somewhat lower than reported in the literautre for an altitude of 5,000-6,000 feet. Van Liere (17) refers to data obtained by Henderson showing an alveolar carbon dioxide tension of $36 \mathrm{~mm}$. $\mathrm{Hg}$ at 6,000 feet. He also refers to a formula proposed by Fitzgerald stating that alveolar carbon dioxide tension decreases approximately $4.2 \mathrm{~mm}$. for each $100 \mathrm{~mm}$. $\mathrm{Hg}$ fall in barometric pressure. Rahn (18) states that the average tension of carbon dioxide is about $5 \mathrm{~mm}$. $\mathrm{Hg}$ lower in Denver, Colorado, than at sea level. It would thus be expected that the arterial carbon dioxide tension at this altitude would be approximately $35 \mathrm{~mm}$. $\mathrm{Hg}$.

Exercise produced no statistically significant effects upon the peripheral arterial and alveolar gas values. However, the mean values for arterial oxygen saturation and alveolar oxygen tension were slightly increased, suggesting that alveolar ventilation is improved by the hyperventilation of exercise. 


\section{SUMMARY}

There are few known studies of pulmonary function of normal, acclimated individuals living at a median altitude ( 1 mile). Therefore, the establishment of "normal" values for the various tests used in measuring pulmonary function was undertaken. Furthermore, the establishment of the effect of this median altitude upon the results of the tests is necessary to interpret them properly. Unfortunately, few studies of pulmonary function have been done in a similar manner at sea level with which to compare these results.

A significant increase in resting minute ventilation is established for this altitude of one mile and minute ventilation is increased during exercise. The increase in ventilation lowers carbon dioxide content and tension in the peripheral arterial blood below values obtained at sea level.

\section{REFERENCES}

1. Van Slyke, D. D., and Neill, J. M., The determination of gases in blood and other solutions by vacuum extraction and manometric measurement. I. J. Biol. Chem., 1924, 61, 523.

2. Riley, R. L., Proemmel, D. D., and Franke, R. E., A direct method for determination of oxygen and carbon dioxide tensions in blood. J. Biol. Chem., 1945, 161, 621.

3. Scholander, P. F., Analyzer for accurate estimation of respiratory gases in one-half cubic centimeter samples. J. Biol. Chem., 1947, 167, 235.

4. Riley, R. L., Lilienthal, J. L., Jr., Proemmel, D. D., and Franke, R. E., On the determination of the physiologically effective pressures of oxygen and carbon dioxide in alveolar air. Am. J. Physiol., 1946, 147, 191.

5. Lilienthal, J. L., Jr., Riley, R. L., Proemmel, D. D., and Franke, R. E., An experimental analysis in man of the oxygen pressure gradient from alveolar air to arterial blood during rest and exercise at sea level and at altitude. Am. J. Physiol., 1946, 147, 199.
6. Baldwin, E. deF., Cournand, A., and Richards, D. W., Jr., Pulmonary insufficiency. I. Physiological classification, clinical methods of analysis, and standard values in normal subjects. Medicine, 1948, 27, 243.

7. Greifenstein, F. E., King, R. M., Latch, S. S., and Comroe, J. H., Jr., Pulmonary function studies in healthy men and women 50 years and older. J. Appl. Physiol., 1952, 4, 641.

8. Rahn, H., and Hammond, D., Vital capacity at reduced barometric pressure. J. Appl. Physiol., 1952, 4, 715 .

9. Austrian, R., McClement, J. H., Renzetti, A. D., Jr., Donald, K. W., Riley, R. L., and Cournand, A., Clinical and physiologic features of some types of pulmonary diseases with impairment of alveolarcapillary diffusion; the syndrome of "alveolar-capillary block." Am. J. Med., 1951, 11, 667.

10. Yu, P. N. G., Lovejoy, F. W., Jr., Hulfish, B., Howell, M. M., Joos, H. A., Tenney, S. M., Haroutunian, L. M., and Evans, H. W., Cardio-respiratory responses and electrocardiographic changes during exercise before and after intravenous digoxin in normal subjects. Am. J. M. Sc., 1952, 224, 146.

11. Schneider, E. C., Physiological effects of altitude. Physiol. Rev., 1921, 1, 631.

12. Gray, J. S., Pulmonary Ventilation and Its Physiological Regulation. (Publication No. 63. American Lecture Series.) Charles C Thomas, Springfield, Ill., 1950.

13. Bruce, R. A., Pearson, R., Lovejoy, F. W., Jr., Yu, P. N. G., and Brothers, G. B., Variability of respiratory and circulatory performance during standardized exercise. J. Clin. Invest., 1949, 28, 1431.

14. Wright, G. W., Maximum oxygen consumption for work periods of six minutes' duration in normal and pathological subjects. Science, 1950, 112, 423.

15. Dill, D. B., and Penrod, K. E., Man's ceiling as determined in the altitude chamber. J. Appl. Physiol., 1948, 1, 409.

16. Riley, R. L., and Cournand, A., "Ideal" alveolar air and the analysis of ventilation-perfusion relationships in the lungs. J. Appl. Physiol., 1949, 1, 825.

17. Van Liere, E. J., Anoxia: Its Effect on the Body. University of Chicago Press, Chicago, 1942.

18. Rahn, H., in Methods in Medical Research, edited by J. H. Comroe, Jr. Volume 2, page 224, Year Book Publishers, Chicago, Ill. 1950. 